\title{
DE VENNOOTSCHAPSRECHTELIJKE POSITIE VAN DE GECONSOLIDEERDE JAARREKENING
}

\section{door Mr.C. R. C. Wijckerbeld Bisdom}

Wie zich gesteld ziet voor de vraag wat de vennootschapsrechtelijke positie is van de geconsolideerde jaarrekening, zal uiteraard in de eerste plaats de bepalingen van het Wetboek van Koophandel opslaan, die betrekking hebben op ,de naamloze vennootschap". Naar de term ,geconsolideerde jaarrekening” zoekt hij dan evenwel vergeefs. De wet spreekt van „balans en winst- en verliesrekening” zonder meer, en het begrip consolidatie is haar vreemd.

Voor de balans en winst- en verliesrekening worden voorschriften gegeven: $\mathrm{Zij}$ worden opgemaakt door het bestuur, met een toelichting, en ter vaststelling voorgelegd aan de algemene vergadering van aandeelhouders (art. $42 \mathrm{~K}$ ). Bepaalde posten moeten afzonderlijk in de balans worden opgenomen (art. $42 \mathrm{~K}$ ). In zekere contrôle op en publicatie van de stukken wordt voorzien (art. 42a, 42b, 42c K). Voor de waarheid (eigenlijk: het niet misleidend zijn) van deze stukken zijn bestuur en commissarissen specifiek aansprakelijk (art. 49b, $52 \mathrm{~K}$ ).

Niet alleen dat de wet van geconsolideerde jaarstukken niet spreekt, zij bedoelt zelfs bepaaldelijk, in de aangehaalde artikelen, dat stukken, alleen betrekking hebbende op elke afzonderlijke vennootschap, - en dus: niet geconsolideerde stukken - worden opgemaakt. Dit blijkt onmiddellijk bij lezing van de opsomming der activa, die als afzonderlijke actiefposten in de balans vermeld moeten worden. Met kas, vorderingen, fondsen, zaken enz. zijn gemeend: de kas, vorderingen, fondsen en zaken van ,de" vennootschap. Niet de activa van enige andere vennootschap, al zouden met deze vennootschap banden, van welke aard ook, bestaan. Bovendien de "deelnemingen" in andere ondernemingen en de vorderingen op ondernemingen waarin is deelgenomen, moeten afzonderlijk worden opgenomen (art. $42 \mathrm{~K})$.

De balans en winst- en verliesrekening van de wet zijn dus de balans en winst- en verliesrekening, opgemaakt voor elke naamloze vennootschap afzonderlijk. Het zijn deze jaarstukken, die aan de algemene vergadering ter vaststelling overgelegd moeten worden, en waarvan publicatie dient plaats te vinden. Een naamloze vennootschap die in plaats daarvan alleen een geconsolideerde jaarrekening voorlegt, verschaft wellicht haar aandeelhouders meer doeltreffende informatie - zij handelt in strijd met de wet ${ }^{1}$ ). Art. $435 \mathrm{~g}$ Wetboek van Strafrecht bedreigt de bestuurders van een dergelijke vennootschap met hechtenis of geldboete.

De "geconsolideerde jaarrekening" is intussen niet beperkt tot de naamloze vennootschap. Het is denkbaar dat een vennootschap onder firma, een commanditaire vennootschap, zelfs dat een enkele natuurlijke persoon heeft deelgenomen in een of meer ondernemingen die in de vorm ener juridisch gescheiden eenheid worden gedreven, en die, bedrijfshuishoudkundig, voor consolidatie in aanmerking zouden komen. Volgens art. 6 Wetboek van Koophandel is ieder die een bedrijf uitoefent verplicht, binnen de eerste zes maanden van elk jaar een naar de eisen van zijn bedrijf ingerichte balans op te maken, en deze eigenhandig te ondertekenen. De vraag kan rijzen of aan deze verplichting door het opmaken van een geconsolideerde balans wordt voldaan.

Naar mijn mening moet deze vraag eveneens ontkennend worden beantwoord.

1) Aldus ook van der Grinten, Geconsolideerde jaarcijfers, N.V. 38 blz. 71, vlg. ook Scheffer, Economie 25 blz. $44 \mathrm{vlg}$.

$\mathrm{mab}$ blz. 122 
De wet stelt hier aan de inrichting van de balans geen enkele eis, noch geeft zij enige nadere omschrijving van hetgeen met dit woord wordt bedoeld. In zoverre zou er dus geen beletsel zijn om daaronder ook te verstaan, wat wij thans een geconsolideerde belans noemen. Evenmin is daartegen een bezwaar, dat ten tijde van de invoering van de bepaling - 1838! - de geconsolideerde jaarrekening nog wel even onbekend zal zijn geweest als vliegtuigen of atoombommen. $\mathrm{Er}$ is in beginsel immers geen bezwaar tegen de interpretatie van een wetstekst aan te passen aan de omstandigheden, zoals die zich in de loop der tijden wijzigen. Doch het is dunkt mij wel zo, dat de wetgever in art. $6 \mathrm{~K}$ het oog had op een balans betreffende de activa en passiva van de koopman zelf, of, zoals het sedert 1934 heet, van degene die een bedrijf uitoefent. De bepaling sluit aan op het eerste lid van het artikel, sprekende over de verplichting aantekening te houden „van zijn vermogenstoestand en van alles, wat zijn bedrijf betreft". Een geconsolideerde balans heeft echter par définition niet betrekking op "het” bedrijf van de betrokkene, maar op twee of meer bedrijven van verschillende (rechts)personen. Daarbij komt, dat de wetgever, voorschriften gevende omtrent de boekhouding van bedrijven, daarbij in het bijzonder gedacht heeft aan de belangen van crediteuren. Voor hen is bij uitstek van gewicht, dat de vermogenstoestand van de debiteur zelf, het zij natuurlijke of rechtspersoon, wordt vastgelegd. In gegevens omtrent andere personen, ook al bestaat met deze een nauwe economische band, zijn zij niet rechtstreeks geinteresseerd.

Een bepaling, welke in dit verband van belang zou kunnen zijn komt ten slotte nog voor in art. 30 van de Wet op de Coöperatieve Verenigingen 1925, waar gesproken wordt van een jaarlijkse rekening en verantwoording door het bestuur. $\mathrm{Er}$ is geen aanleiding te geloven dat hier, anders dan elders, geconsolideerde cijfers aan de wettelijke eis zouden voldoen.

Tenslotte zou ik nog even willen stilstaan bij een bepaling, gelegen aan de peripherie van wat men gemeenlijk het vennootschapsrecht pleegt te noemen, namelijk art. 336 Wetboek van Strafrecht:

„De koopman, de bestuurder, beherende vennoot of commissaris ener vennootschap of coöperatieve vereniging, die opzettelijk een onwaren staat of ene onware balans, winst- en verliesrekening of toelichting op een dier stukken openbaar maakt of zodanige openbaarmaking opzettelijk toelaat, wordt gestraft met gevangenisstraf van ten hoogste een jaar".

Ziet dit artikel alleen op de opzettelijke openbaarmaking van een onware balans of winst-en verliesrekening in dezelfde, beperkte zin als deze termen worden gebezigd in de andere hiervoor vermelde wetsartikelen? Er is historisch een band met speciaal de art. 42 vlg. van het Wetboek van Koophandel. Bij de invoering van deze bepalingen, is ook art. $336 \mathrm{Sr}$. gewijzigd om de tekst daarvan te doen aansluiten. Dit behoeft evenwel niet te leiden tot de conclusie, dat de opzettelijke publicatie van een onware geconsolideerde jaarrekening aan de greep van de strafrechter zou zijn onttrokken. Het schijnt mij niet bepaald noodzakelijk hier onder balans en winst- en verliesrekening alleen die stukken te verstaan, die beantwoorden aan de eisen, die het Wetboek van Koophandel daaraan stelt. ${ }^{2}$ ) Het strafwaardige van het feit is niet daarin gelegen, dat juist deze, in de wet bekende stukken onwaar zijn, maar veeleer, dat derden bedrogen worden in stuk-

2) Zo pleegr men ook strafbaar te achten de openbaarmaking van de onware jaarstukken in geval deze openbaarmaking door de wet niet is voorgeschreven (dus voor de zogenaamde besloten vennootschappen) - van der Heyden - van der Grinten nr. 262.

m a b blz. 123 
ken, die in het maatschappelijke leven een zeker vertrouwen genieten. Men zal dan onder balans en winst- en verliesrekening mogen verstaan al die stukken, die in het maatschappelijk verkeer aldus betiteld worden, en aan welke dit vertrouwen wordt geschonken. Daaronder vallen ook geconsolideerde jaarstukken. Een dergelijke ruime uitlegging is te meer gerechtvaardigd, nu art. $336 \mathrm{Sr}$. mede spreekt van een onware ,staat”, een term die stellig niet op een enge toepassingsmogelijkheid duidt. Daarenboven zou het opmaken van een valse geconsolideerde balans strafbaar kunnen zijn als valsheid in geschrifte (art. 225 Wetboek van Strafrecht), nu de Hoge Raad aanneemt, dat een balans is een geschrift met bewijsbestemming, en dit voor een geconsolideerde balans eveneens kan gelden. ${ }^{3}$ )

Een eerste overzicht van de vennootschapsrechtelijke bepalingen leidt dus tot de slotsom, dat de geconsolideerde jaarrekening door de wet eigenlijk wordt genegeerd, en dat zij slechts, onverwachterwijze, in het strafrecht op een zekere bescherming aanspraak zou kunnen maken.

Met een dergelijk overzicht van de voorschriften, die bepaaldelijk de jaarstukken tot onderwerp hebben, is het onderwerp echter niet uitgeput. Het zou kunnen zijn dat de geconsolideerde jaarrekening haar intreden in het vennootschapsrecht had gedaan via enige bepaling van meer algemene strekking, die niet van jaarstukken in het bijzonder spreekt.

Daarbij komen in de eerste plaats in aanmerking de bepalingen omtrent taak en verantwoordelijkheid van de bestuurders van naamloze vennootschappen. De bestuurder is tegenover de vennootschap gehouden tot een behoorlijke vervulling der hem opgedragen taak (art. 47c). Zou het bestuur een geconsolideerde jaarrekening publiceren waarop gegronde aanmerking viel te maken, dan zouden de bestuurders hoofdelijk tegenover de vennootschap aansprakelijk zijn. Deze aansprakelijkheid zou zich evenwel ook kunnen uitstrekken ten behoeve van derden. Met name wanneer de publicatie als een onrechtmatige daad beschouwd zou kunnen worden - naar de bekende definitie van de Hoge Raad: wanneer zij zou indruisen tegen de zorg, die in het maatschappelijk verkeer betaamt ten opzichte van eens anders goed - zouden de bestuurders ook aansprakelijk zijn voor schaden, als gevolg van zulk een publicatie door derden geleden. En de vennootschap met hen. ${ }^{4}$ )

Geconsolideerde jaarcijfers plegen in het bijzonder ook dan verstrekt te worden, wanneer de vennootschap een beroep op de kapitaalmarkt wil doen. Dan geldt de bijzondere aansprakelijkheid, omschreven in de art. 1416a vlg. B.W., kort aangeduid als de aansprakelijkheid voor het prospectus. De vennootschap is dan, met haar bestuurders en commissarissen, aansprakelijk voor de openbaarmaking van gegevens, welke, doordien zij onwaar, onvolledig of verminkt zijn een onjuiste voorstelling moeten wekken. Het lijdt geen twijfel, dat onder die gegevens ook geconsolideerde jaarstukken begrepen kunnen worden. Arr. 335 Wetboek van Strafrecht geeft hier het strafrechtelijke sluitstuk.

Aan het slot van dit gedeelte mijner beschouwingen kan ik constateren dat de „,vennootschapsrechtelijke positie van de geconsolideerde jaarrekening" bescheiden is, nauwelijks afwijkend van die van andere financiële gegevens, in welke vorm ook door de vennootschap openbaar gemaakt.

\footnotetext{
3) H. R. 1 febr. 1904 W 8027.

4) Vgl. omtrent het publiceren van onjuiste gegevens betreffende de financiële toestand van een vennootschap als grond voor schadevergoeding H.R. 25 nov. 1927. 1928. 364.
}

$\mathrm{m}$ a b blz. 124 
Moet men zich over dit resultaat verwonderen? Mijns inziens niet.

In de eerste plaats, de wetgever van 1928 heeft zijn aandacht gericht op de naamloze vennootschap als rechtspersoon op zichzelf. De aandeelhouders ziet hij als de kapitaalverschaffers die actieve belangstelling in de bedrijfsvoering hebben, en daarom, zoals het, overigens minder juist, veelal heet, de hoogste macht hebben. In hun vergaderingen worden de belangrijke beslissingen, de N.V. betreffende, besproken en genomen. Bovendien zijn de schuldeisers van de N.V. onderwerp van de bijzondere zorg van de wet. In dit kader is een geconsolideerde jaarrekening, voor extern gebruik, minder belangrijk, terwijl de wet geen bemoeienis heeft met de gegevens, waarvan de N.V. zich binnen haar bedrijfsorganisatie bedient. De aandeelhouder-belegger daarentegen, die geen zeggenschap in de vennootschap wil uitoefenen, doch alleen, al dan niet via financiële pers of beleggingsdeskundigen, inlichtingen wil ontvangen, over vermogenspositie, groei en winstmogelijkheden van deze, is niet het type, waarop onze wettelijke regeling is toegespitst.

In de tweede plaats, en dit houdt met het voorgaande verband, de wet heeft geen weet van die combinaties van (rechts)personen, die als „concern" of „groep" een economische eenheid vormen, en daarbij voor de landsgrenzen veelal geen halt houden ${ }^{5}$ ). Toch is het verschijnsel van de concernvorming er één dat ook in het vennootschapsrecht tot uiting komt. Blijkens de jurisprudentie zijn er in de loop der jaren dan ook wel vragen gerezen die met deze concernverhoudingen samenhingen. Een vennootschap verplicht zich tegenover een andere zich te onthouden van de vervaardiging van een bepaald produkt. Is het rechtens toelaatbaar, dat een dochter van eerstgenoemde vennootschap de vervaardiging ter hand neemt? Kunnen, zo nodig, vorderingen op de moeder gecompenseerd worden met schulden aan de dochter, en omgekeerd? Kan de onderhuurder een beroep op huurbescherming doen tegenover de eigenaar-verhuurder, wanneer de huurder-onderverhuurder een dochter van laatstgenoemde is? Is het gebruik van een merk door een dochtervennootschap gelijk te stellen aan gebruik door de moeder? In al deze en dergelijke gevallen is men, voorzover mij bekend, wel tot bevredigende oplossingen kunnen komen, ook zonder enige wettelijke voorschriften betreffende het „concern” als zodanig. Het vennootschapsrecht is soepel genoeg, en laat voldoende ruimte voor het opereren met zeer algemene begrippen als redelijkheid, billijkheid en uitvoering te goeder trouw. Het is echter wel duidelijk dat een vennootschapsrecht, dat het "concern” niet kent, ook weinig aandacht zal besteden aan geconsolideerde jaarstukken.

In de derde plaats, op gevaar af van door meer deskundigen onmiddellijk terechtgewezen te worden, ik zou willen veronderstellen, dat in 1928 het begrip geconsolideerde jaarrekening in Nederland nog slechts een beperkte belangstelling genoot, en allerminst vast omlijnd was. Is dit laatste thans anders geworden?

Oppervlakkige kennisneming van hetgeen de experts op dit gebied hebben geschreven, geeft mij de indruk dat omtrent de vragen wanneer en hoe geconsolideerd dient te worden nog geen eenstemmigheid bestaat. Is het wonder als de wetgever met betrekking tot een ,technisch" onderwerp als dit, de maatschappelijke ontwikkeling volgt, in plaats van op deze vooruit te snellen? Zolang en in zoverre in de wereld der direkt betrokkenen en hun adviseurs niet algemeen aanvaarde opvattingen bestaan omtrent de consolidatie en de daaraan verbonden vraagstukken, valt moeilijk te verwachten dat de wet zich van dergelijke, nog weinig vaststaande begrippen zal bedienen.

5) Ik laat hier, zoals elders, de belastingrechtelijke aspecten terzijde. 
$\mathrm{B}_{\mathrm{ij}}$ deze stand van zaken is derhalve begrijpelijk, dat de geconsolideerde jaarrekening nog niet of nauwelijks haar eigenlijke intrede in ons vennootschapsrecht heeft gedaan.

Edoch, wat niet is kan komen. Hoe zijn de vooruitzichten thans, nu het denkbeeld der consolidatie, ondanks daaraan klevende onzekerheden, wel gemeen goed is geworden?

Alvorens te trachten op deze vraag een antwoord te geven zou ik een, zij het vluchtige, blik naar het buitenland willen slaan. Is daar de geconsolideerde jaarrekening in het vennootschapsrecht bekend en erkend, en zo ja, in welke vorm?

In Frankrijk en België is geen enkel aanknopingspunt te vinden. Het vennootschapsrecht negeert de consolidatie, evengoed als hier te lande het geval is.

Belangwekkender is de toestand in de Duitse Bondsrepubliek. Reeds in 1931 werd in het Handelsgesetzbuch een Paragraph $261 \mathrm{~d}$ ingevoerd, luidende als volgt:

„Die Reichsregierung wird ermächtigt, für Konzerngesellschaften Vorschriften über die Aufstellung des eigenen und über die Aufstellung eines gemeinschaftlichen Jahresabschlusses zu erlassen".

Een in hoofdzaak overeenkomstige bepaling is in het Aktiengestez van 1937 opgenomen (par. 134). Vermelding verdient daarbij, dat deze wet ook het begrip „Konzern” en „Konzernunternehmen” invoerde (par. 15).

Dit moge zeer schoon lijken voor degene, die de geconsolideerde jaarstukken tot deel van het vennootschapsrecht zou willen maken, het is niettemin de vraag of juist uit deze bepalingen niet blijkt, dat de tijd daarvoor, althans in Duitsland nog niet rijp was. Immers, van de wettelijke machtiging is tot dusverre geen gebruik gemaakt.

Wel heeft het enkele bestaan van de aangehaalde bepalingen bewerkstelligd, dat het onderwerp: verplichte publicatie van geconsolideerde jaarstukken, in de Duise rechtslitteratuur aanmerkelijke belangstelling heeft gevonden. Trouwens de concernvorming, en de juridische gevolgen daarvan, zijn bij onze Oosterburen meer bestudeerd dan hier te lande.

Tenslotte is dan ook in het thans aanhangige ontwerp voor een nieuw „Aktiengesetz” de verplichting tot het openbaar maken van „Konzernabschlüsse und Konzerngeschäftsberichte" opgenomen in paragraaf 317 en vlg., en daar uitvoerig uitgewerkt. Volgens de bepalingen van de zogenaamde „kleine Aktienrechtsreform" moeten deze voorschriften reeds in de jaarverslagen per 31 december 1960 worden in acht genomen.

Is dus, met deze laatste uitzondering, het beeld van de ons op het vasteland omringende landen niet al te hoopgevend, geheel anders is de situatie in het Verenigd Koninkrijk. De Companies Act 1948 geeft uitvoerige voorschriften over de „obligation to lay group accounts before holding company" (section 150), waaruit ik citeer het eerste lid:

„(1) Where at the end of its financial year a company has subsidiaries, accounts or statements (in this Act referred to as ,group accounts") dealing as hereinafter mentioned with the state of affairs and profit or loss of the company and the subsidiaries shall, subject to the next following subsection. be laid before the company in general meeting when the company's own balance sheet and profit and loss account are so laid".

Over vorm en inhoud van dergelijke group accounts handelen de Sections 151 en 152, en volgens het eerste artikel (lid (1)):

m a b blz. 126 
„Subject to the next following subsection, the group accounts laid before a holding company shall be consolidated accounts comprising:

(a) a consolidated balance sheet dealing with the state of affairs of the company and all the subsidiaries to be dealt with in group accounts;

(b) a consolidated profit and loss account dealing with the profit or loss of the company and those subsidiaries".

Bepalingen omtrent het boekjaar van de holding en de subsidiary, en definities van deze begrippen voltooien het beeld. Tenslotte geeft de zgn. Eight Schedule, behorende bij de Act, gedetailleerde voorschriften omtrent de wijze waarop balans en winst- en verliesrekening ingericht moeten worden, waarin de ,group accounts" en de consolidatie allerminst vergeten worden.

In de Verenigde Staten kan niet gezegd worden dat de consolidated statements algemeen in de wetgeving van de verschillende staten zijn opgenomen, al zijn er enkele uitzonderingen. Wel is het zo, dat de Securities and Exchange Commission (S.E.C.) de bevoegdheid heeft, en daarvan ook geregeld gebruik maakt, consolidated statements voor te schrijven. Insgelijks worden deze verlangd door de New York Stock Exchange als een voorwaarde voor de notering.

Tenslotte dan de toekomstverwachtingen voor de geconsolideerde jaarrekening in het Nederlands vennootschapsrecht. Dit gedeelte van het recht staat tegenwoordig in het middelpunt van de belangstelling van hen die naar verandering streven. Wellicht is dit een geschikte tijd om ook plaats te verschaffen aan de geconsolideerde jaarrekening.

Het ligt voor de hand dan in de eerste plaats te denken aan een wijziging van het voorschrift, dat de verplichting tot vaststelling van de vennootschappelijke balans en winst- en verliesrekening regelt, en de eisen opsomt, waaraan eerstgenoemd stuk moet voldoen, art. $42 \mathrm{~K}$. Men bedenke evenwel, dat in het kader van de herziening van het Burgerlijk Wetboek het vennootschapsrecht in dit nieuwe Wetboek zal worden opgenomen, in boek II daarvan, en dat de tekst van dit boek reeds wet is geworden, al ligt het tijdstip van invoering nog in de onzekere toekomst. ${ }^{7}$ ) Er is, behoudens zekere uitzonderingen, die ik hier terzijde kan laten, niet naar gestreefd het geldende vennootschapsrecht bij deze gelegenheid te wijzigen, en voor de meeste artikelen van het Wetboek van Koophandel is het dus bij een nieuwe aanduiding en nummering gebleven. Prof. Meyers heeft echter in zijn ontwerp juist met betrekking tot art. 42 een wijziging voorgesteld: De opsomming van de "afzonderlijke posten" die in de balans ener naamloze vennootschap moeten voorkomen, is vervangen door de enkele zin:

„Omtrent de inrichting van de balans en de winst- en verliesrekening worden bij algemene maatregel van bestuur voorschriften gegeven". (art. 2.3.3.13)

De toelichting op dit voorstel luidt:

„De voorschriften, welke de wet in art. 42 lid 3 W.v.K. geeft omtrent de inrichting van de balans en de winst- en verliesrekening zijn weinig bevredigend en de voorlichting, door de N.V. gegeven, is dan ook menigmaal als ten enen male onvoldoende te beschouwen. Door mogelijk te maken, dat $z$ waardere eisen t.a.v. deze voorlichting worden gesteld, kan mede tegemoet worden gekomen aan hen, die een scherpere controle op de financierings-

i) Wet van 12 mei $1960 \mathrm{~S} 45$.

m a b blz. 127 
politiek van de N.V. wensen (zie o.a. Sanders in Feestbundel Cleveringa p. 329-362). Ten einde de nodige soepelheid te waarborgen, wordt voorgesteld, dat voorschriften nopens balans etc. bij algemene maatregel van bestuur zullen worden gegeven; deze voorschriften zullen voor verschillende soorten naamloze vennootschappen verschillend kunnen zijn. Een nadere sanctie is niet voorgesteld. $\mathrm{Zij}$ wordt overgelaten an de werking der maatschappelijke krachten".

De voorgestelde bepaling is aldus in de wet overgenomen. Bij de behandeling in de Eerste Kamer heeft het lid van Meeuwen zich afgevraagd of dit voorschrift, dat hem zo bijzonder nuttig leek, wat vroeger ingevoerd zou kunnen worden dan het nieuwe Burgerlijk Wetboek. De Minister stond daartegenover niet geheel afwijzend. Overigens „,vroeger dan het nieuwe Burgerlijk Wetboek” betekent nog niet hetzelfde als , binnen enkele jaren”.

Men kan zich denken, dat wanneer aldus de wettelijke voorschriften omtrent de balans en de winst- en verliesrekening herzien worden, daarin ook de geconsolideerde cijfers een plaats zullen krijgen. De publicatie van de Dr Wiardi-Beckman Stichting "De hervorming van de onderneming" zegt positief:

„Wat het gecompliceerde probleem van de jaarverslaggeving van moeder- en dochtermaatschappijen betreft, zal men ervan uit dienen te gaan dat een zgn. geconsolideerde balans zal moeten worden samengesteld, wanneer een N.V. een meerderheidsbelang in een andere N.V. heeft."

Hier opent zich voor de geconsolideerde jaarrekening dus de direkte toegang tot het eigenlijke vennootschapsrecht. Of de zaak evenwel zo eenvoudig ligt als in de aangehaalde passage wordt verondersteld, waag ik te betwijfelen. Men zal nauwkeurig moeten omschrijven wanneer consolidatie verplicht zal zijn. Zal een term als ,meerderheidsbelang" daarvoor, in de ogen van bedrijfshuishoudkundigen en juristen, een voldoende en een juist criterium opleveren? En is het waar dat ieder „meerderheidsbelang” een verplichting tot consolidatie moet scheppen? Op welke wijze zal een dergelijke consolidatie moeten plaats vinden? Dient consolidatie ook te worden voorgeschreven bij vennootschappen wier aandelen niet ter beurze genoteerd zijn? Ziedaar een aantal vragen, waarvoor men dan gesteld zal worden.

Nu kan men zeggen dat, wanneer de vereisten waaraan de balans en de winst- en verliesrekening moeten voldoen, niet meer in de wet staan, doch bij Algemene Maatregel van Bestuur worden vastgesteld, deze op betrekkelijk eenvoudige wijze gewijzigd kunnen worden. Kiest men dus bepalingen, die in de praktijk niet blijken te voldoen, of die tegen juiste theoretische inzichten blijken in te druisen, dan kunnen deze weer veranderd worden. Toch zou een dergelijke beweeglijkheid in de voorschriften door het bedrijfsleven weinig op prijs worden gesteld. Men zal dus verstandig doen consolidatie alleen voor te schrijven voor die gevallen, waarin redelijkerwijze geen verschil van mening omtrent de wenselijkheid van dit procédé kan bestaan.

In dit verband vraag ik nog de aandacht voor een opmerking, gemaakt in het Voorlopig Verslag van de Tweede Kamer der Staten-Generaal, namelijk of er - gezien de ingrijpende bevoegdheid, welke in dit artikel aan de Kroon wordt gegeven - wellicht aanleiding bestaat, te bepalen, dat de algemene maatregel binnen een zekere termijn moet worden gevolgd door een wet ${ }^{8}$ ). De Minister bleek

8) Bijl. Hand. 2e Kamer 1956. $57 \mathrm{nr} 3769 \mathrm{nr} 4$ blz. 44.

$\mathrm{mab}$ blz. 128 
hiervoor niet veel te gevoelen, en het artikel is dan ook onveranderd wet geworden. Niettemin kan er gegronde twijfel bestaan of wenselijk is, dat op dit terrein de overheid zonder enige Parlementaire contrôle regels stelt, die bijv. ook differentiatie tussen verschillende soorten N.V.'s kunnen inhouden. Langs deze weg wordt een mogelijkheid van overheidsbemoeiing met het bedrijfsleven geopend, die zeer ver kan gaan. Daartegenover spreken de argumenten voor een delegatie van in wezen wetgevende bevoegdheid hier niet sterk, omdat het straks alleen gaat om de wettelijke minimum eisen, die aan de externe verslaggeving te stellen vallen, en die de maatschappelijke ontwikkeling niet per se op de voet behoeven te volgen. Evenmin als zij dit tot dusverre hebben gedaan.

Kan, bij het wettelijk voorschrijven van geconsolideerde jaarstukken, de zgn. balansaansprakelijkheid van bestuurders en commissarissen ongewijzigd worden gehandhaafd? (art. 49b, $52 \mathrm{~K}$ ). De mogelijkheid bestaat, dat door de geconsolideerde stukken „een misleidende voorstelling wordt gegeven”, en dat de leidende functionarissen van de vennootschap daaraan geheel vreemd zijn omdat zij, noodzakelijkerwijze, zijn afgegaan op gegevens van dochterondernemingen, met geheel andere bestuurders. Reeds thans bestaat er evenwel een veiligheidsklep: de bestuurder (commissaris) die bewijst, dat de misleidende voorstelling niet aan hem te wijten is, gaat vrijuit. Accountantscontrôle bij de dochtermaatschappijen zal daarom vrijwaren voor aansprakelijkheid. Dit komt voldoende voor om ook in de opgeworpen moeilijkheid met betrekking tot een geconsolideerde jaarrekening te voorzien.

Hoe dit alles ook zij, er zal in de toekomst een mogelijkheid bestaan nadere bindende voorschriften te geven omtrent de inrichting van de jaarstukken van die vennootschappen, die tot openbaarmaking daarvan gehouden zijn. Daarbij zal men, naar het mij voorkomt, in zekere gevallen ook geconsolideerde cijfers kunnen voorschrijven. De geconsolideerde jaarstukken zullen dan rechtens dezelfde betekenis hebben en dezelfde bescherming genieten als de balans en winst- en verliesrekening van de enkele vennootschap. Het opmaken van deze laatste stukken zal daarnaast echter wel een verplichting blijven. Hoever men zal gaan in het voorschrijven van consolidaties is nog niet met zekerheid te zeggen. Het rapport van de Commissie Jaarverslaggeving van de werkgeversorganisaties (1955) gaat niet verder, dan een geconsolideerde balans te noemen ,de aangewezen weg” in "de meeste gevallen" waarin er een groter aantal dochterondernemingen is. In het Fondsenreglement van de Vereniging voor den Effectenhandel wordt het vereiste van overlegging van geconsolideerde jaarrekening niet met zoveel woorden genoemd. Men staat dus aan het begin van een nieuw element in het vennootschapsrecht, en men zal zich moeten hoeden de boog te strak te spannen: de wet geeft slechts een minimum, waaraan ten minste moet worden voldaan. Voor wat de wetgever betreft zal men zich kunnen aansluiten bij de toelichting tot het hiervoor genoemde Duitse ontwerp, waar gezegd wordt „Bei der Ausarbeitung der Vorschriften über den Konzernabschlusz war zu berücksichtigen, dass der Gesetzgeber mit diesen Vorschriften Neuland betritt. Daher erschien es angebracht, vorsichtig und schrittweise vorzugehen, um es der Wirtschaft zu ermöglichen, reibungslos in die neuen Vorschriften hineinzuwachsen." Daarnaast en daarboven zal de geconsolideerde jaarrekening zich voornamelijk moeten ontwikkelen in de praktijk van het maatschappelijk leven, zoals zij dit tot dusverre ook heeft gedaan. Van de Vereniging voor Effectenhandel kan daarbij, in de eisen die zij aan de notering kan stellen, een stimulerende invloed uitgaan.

m a b blz. 129 